\title{
Assessment of Uncertainties in Projected Temperature and Precipitation over the Arabian Peninsula Using Three Categories of Cmip5 Multimodel Ensembles
}

\author{
Mansour Almazroui $^{1}$ - M. Nazrul Islam ${ }^{1} \cdot$ Sajjad Saeed $^{1,2} \cdot$ Abdulrahman K. Alkhalaf $^{1} \cdot$ Ramzah Dambul $^{1}$
}

Received: 6 October 2017 / Accepted: 15 November 2017 / Published online: 22 November 2017

(c) The Author(s) 2017. This article is an open access publication

\begin{abstract}
Background Projections of temperature and precipitation with low uncertainties are key parameters to climate changerelated studies.

Purpose The projected temperature and precipitation and their uncertainties over the Arabian Peninsula for the 21st century for three CMIP5 multimodel ensembles under RCP4.5 and RCP8.5 are examined in this paper.

Methods Analyzing the performance of 30 CMIP5 model individually, they are categorized into three groups for the present climate (1976-2005). By applying simple model averaging ensemble method, three multimodel ensemble means, namely: (i) all CMIP5 models ensemble (AME), (ii) selected CMIP5 models ensemble (SME), and (iii) best-performing CMIP5 models ensemble (BME) are developed.

Results Over the Arabian Peninsula, a continuous rise in temperature is obtained in all three ensembles (i.e., AME, SME, and BME) in the 21st century. The BME shows enhanced changes in temperature at the end of 21 st century as compared to AME and SME. Moreover, the BME shows a remarkable reduction in uncertainties for the projected temperature. The AME, SME, and BME show strong inter-annual variability for the projected precipitation over the peninsula. Compared to AME and SME, the BME revealed enhanced positive change in the annual mean precipitation by the end of 21 st century.

Conclusions Regionally, southern/northwestern areas of the peninsula receive enhanced/reduced future precipitation as compared to the present climate. The differences in the projected precipitation and temperature signals increase largely between the three ensembles towards the end of 21 st century. Therefore, it is concluded that selecting the best-performing models may lead a better planning by the policy makers and stakeholder for the region.
\end{abstract}

Keywords Uncertainties $\cdot$ Climate models $\cdot$ CMIP5 $\cdot$ Arabian Peninsula $\cdot$ Future projections

\section{Introduction}

Climate change is the greatest threat to the life and livelihood on earth. The increasing future extremes in the form of natural hazards such as droughts and floods impose serious

Electronic supplementary material The online version of this article (https://doi.org/10.1007/s41748-017-0027-5) contains supplementary material, which is available to authorized users.

Mansour Almazroui

mansour@kau.edu.sa

1 Center of Excellence for Climate Change Research / Department of Meteorology, King Abdulaziz University, 80234, Jeddah 21589, Saudi Arabia

2 Department of Earth and Environmental Sciences, KU Leuven, Leuven, Belgium impacts on various sectors of societal activities. The Intergovernmental Panel on Climate Change (IPCC) has already mentioned in its recent Fifth Assessment Report (AR5) that the global mean temperature will continue to rise in the $21 \mathrm{st}$ century (IPCC 2013). The IPCC climate projections are mainly based on the global climate models simulations. The climate model projections are associated with uncertainties (Qian et al. 2016). There are three main sources that contribute to the uncertainties in the climate projections which are (i) internal variability of the climate system, (ii) inter-model variability, and (iii) variability between different emission scenarios. The internal variability results from the natural variations occurring in the climate system in the absence of the external forcing. The inter-model variability comes from the fact that each model simulates different climate change under the same forcing. This difference mainly comes from 
Table 1 List of CMIP5 models used in this study

\begin{tabular}{|c|c|c|c|c|c|}
\hline & Model & Resolution & RCP4.5 & RCP8.5 & Country \\
\hline 1 & ACCESS1.0 & $1.875^{\circ} \times 1.875^{\circ}$ & $*$ & $*$ & Australia \\
\hline 2 & ACCESS 1.3 & $1.875^{\circ} \times 1.875^{\circ}$ & $*$ & $*$ & Australia \\
\hline 3 & BCC-CSM1.1 & $2.8^{\circ} \times 2.8^{\circ}$ & $*$ & $*$ & China \\
\hline 4 & BCC-CSM1.1 M & $2.8^{\circ} \times 2.8^{\circ}$ & $*$ & $*$ & China \\
\hline 5 & BNU-ESM & $2.8^{\circ} \times 2.8^{\circ}$ & $*$ & $*$ & China \\
\hline 6 & CanESM2 & $2.8^{\circ} \times 2.8^{\circ}$ & $*$ & $*$ & Canada \\
\hline 7 & CCSM4 & $0.9^{\circ} \times 1.25^{\circ}$ & $*$ & $*$ & USA \\
\hline 8 & CESM1-BGC & $0.9^{\circ} \times 1.24^{\circ}$ & $*$ & $*$ & USA \\
\hline 9 & CESM1-CAM5 & $0.9^{\circ} \times 1.25^{\circ}$ & $*$ & * & USA \\
\hline 10 & CMCC-CM & $0.75^{\circ} \times 0.75^{\circ}$ & $*$ & $*$ & Italy \\
\hline 11 & CMCC-CMS & $1.875^{\circ} \times 1.875^{\circ}$ & $*$ & $*$ & Italy \\
\hline 12 & CSIRO-Mk3_0-6 & $1.875^{\circ} \times 1.875^{\circ}$ & $*$ & $*$ & Australia \\
\hline 13 & EC-EARTH & $2.8^{\circ} \times 2.8^{\circ}$ & $*$ & $*$ & Europe \\
\hline 14 & FIO-ESM & $2.8^{\circ} \times 2.8^{\circ}$ & $*$ & $*$ & China \\
\hline 15 & GFDL-ESM2G & $2.5^{\circ} \times 2.0^{\circ}$ & $*$ & $*$ & USA \\
\hline 16 & GFDL-ESM2 M & $2.5^{\circ} \times 2.0^{\circ}$ & $*$ & $*$ & USA \\
\hline 17 & GISS-E2-R & $2.5^{\circ} \times 2.0^{\circ}$ & $*$ & $*$ & USA \\
\hline 18 & HadGEM2-AO & $1.875^{\circ} \times 1.25^{\circ}$ & $*$ & $*$ & South Korea \\
\hline 19 & HadGEM2-CC & $1.875^{\circ} \times 1.25^{\circ}$ & $*$ & $*$ & UK \\
\hline 20 & HadGEM2-ES & $1.875^{\circ} \times 1.25^{\circ}$ & $*$ & $*$ & UK \\
\hline 21 & INMCM4 & $1.5^{\circ} \times 2^{\circ}$ & $*$ & $*$ & Russia \\
\hline 22 & IPSL-CM5A-LR & $2.5^{\circ} \times 1.25^{\circ}$ & $*$ & $*$ & France \\
\hline 23 & IPSL-CM5A-MR & $1.268^{\circ} \times 2.5^{\circ}$ & $*$ & $*$ & France \\
\hline 24 & IPSL-CM5B-LR & $1.9^{\circ} \times 3.75^{\circ}$ & $*$ & $*$ & France \\
\hline 25 & MIROC5 & $1.4^{\circ} \times 1.4^{\circ}$ & $*$ & $*$ & Japan \\
\hline 26 & MPI-ESM-LR & $1.8^{\circ} \times 1.8^{\circ}$ & $*$ & $*$ & Germany \\
\hline 27 & MPI-ESM-MR & $1.8^{\circ} \times 1.8^{\circ}$ & $*$ & $*$ & Germany \\
\hline 28 & MRI-CGCM3 & $1^{\circ} \times 1^{\circ}$ & $*$ & $*$ & Japan \\
\hline 29 & NorESM1-M & $2.5^{\circ} \times 1.9^{\circ}$ & $*$ & $*$ & Norway \\
\hline 30 & NorESM1-ME & $2.5^{\circ} \times 1.9^{\circ}$ & $*$ & $*$ & Norway \\
\hline
\end{tabular}

different sources within a model such as the model resolution, physical parameterization implemented in the global climate models. The third source of uncertainty is associated with different emission scenarios, which represent a different amount of greenhouse gas emissions (and aerosols and their precursors).

There are only a few studies available in the literature (for instance, see Almazroui et al. 2012a, b, 2013, 2016; Al Sarmi and Washington 2011, 2013; Donat et al. 2014; Deng et al. 2015; El Keenawy et al. 2014; Evans 2009; Kwarteng et al. 2009), that are conducted to examine the present climate, future climate projections, and extremes over the study region. The climate projections over the Arabian Peninsula using the CMIP3 data set were examined by
Almazoui et al. (2016). They reported a significant rise in temperature for the Peninsula in the 21 st century. They further showed a decreasing (increasing) trend in precipitation for the northern (southern) peninsula. Due to its geographical location, the annual mean temperature in the Arabian Peninsula observes relatively high. A further increase in the future temperature can be considered as a severe threat to the human and animal lives in the peninsula. The central parts of the Arabian Peninsula observe dry and hot weather conditions throughout the year, whereas the coastal regions are highly humid (Almazroui et al. 2012a, b). If climate change continues unabated, a combination of high future temperatures and humidity could result in extreme heat conditions around the Arabian Gulf and other coastal areas in 


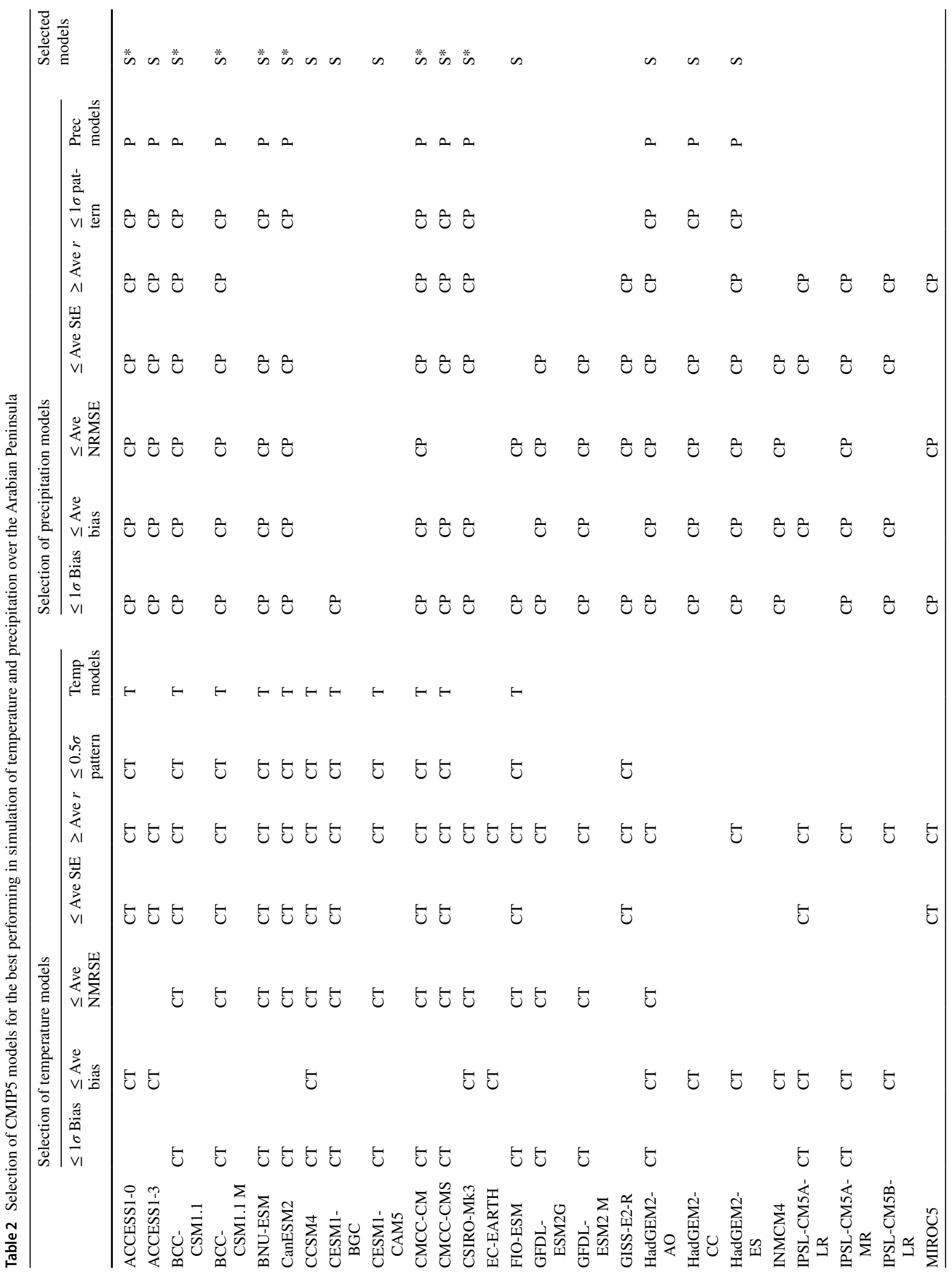




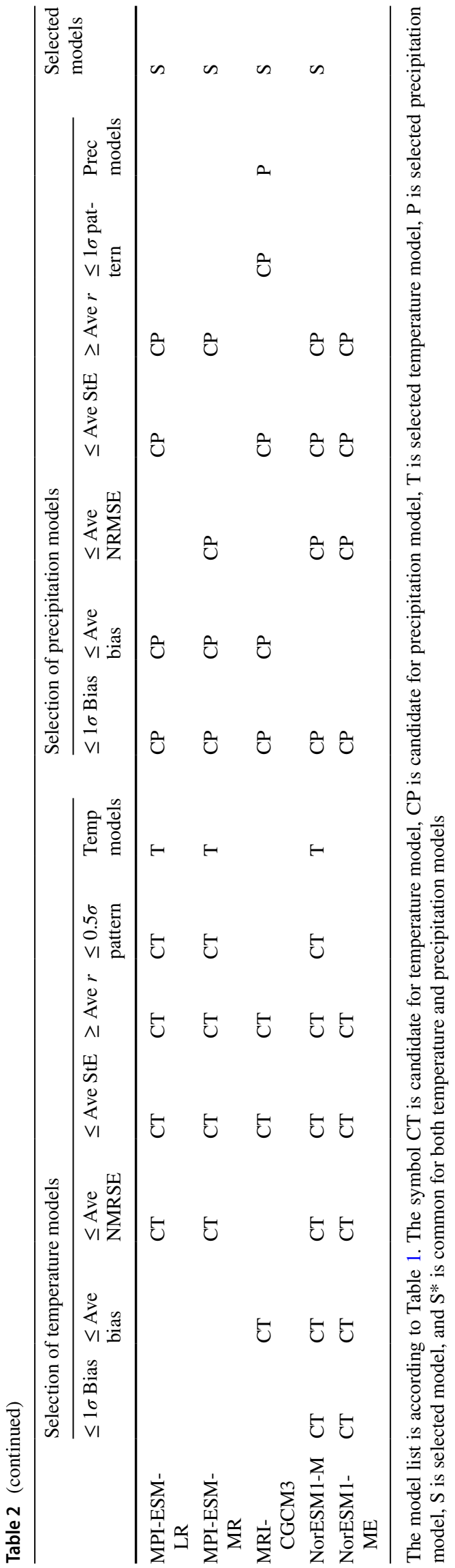

the Arabian Peninsula that will also be intolerable for human life in these areas (e.g. Pal and Eltahir 2016; Schär 2016). The decision makers in the Arab region are, therefore, keen to know about the reliability of the future climate projections made for this region, so they can adequately design adaptation strategies. It is, therefore, important to inform the decision makers about the reliability of the climate projections made for the peninsula.

The CMIP5 data sets are widely used by the scientific community to understand various aspects of global and regional climate. A list of publications can be found at https://cmip-publications.1lnl.gov/search?type=project $\&$ option=CMIP5. The CMIP5 experiments used new generation of global models with improved physical parameterizations and new emission scenarios. These new RCPs (Representative Concentration Pathways) contain information about latest socioeconomic data, new technologies, changes in land cover, and changes in land use (Moss et al. 2010). As mentioned earlier, the future climate projections based on the simulation data are not free from uncertainties, whereas the policy makers are more interested in reasonable future estimates of temperature and precipitation together with a reduction in uncertainties associated with these projections. None of the studies mentioned above analyzed the more updated Climate Model Intercomparison Project, Phase-5 (CMIP5) climate models simulations (Taylor et al. 2012) except Almazroui et al. (2017a). The changes in projected precipitation and temperature over the peninsula were examined by Almazroui et al. (2017a) using a set of 22 CMIP5 models data. The present study further aims to utilize data from larger number (30) of CMIP5 models over the Peninsula. The aim of this study is to examine the changes in projected precipitation and temperature and their corresponding uncertainties for three different multimodel ensembles based on CMIP5 data set. For this purpose, the projected precipitation and temperature over the study region for all available 30 CMIP5 models are examined. In the second step, based on the model performance in the present climate, the 30 CMIP5 models are classified into two more groups. Finally, the difference in the climate change signals and their corresponding uncertainties over the peninsula for these three categories mentioned above are examined.

\section{Data and Methodology}

The main data set employed in this study has been attained from the CMIP5 archives (http://cmip-pcmdi.llnl.gov/ cmip5/index.html). We analyzed monthly mean precipitation and temperature simulation data from 30 CMIP5 models (Table 1). The CMIP5 monthly precipitation and temperature data cover the historical (1901-2005) and 

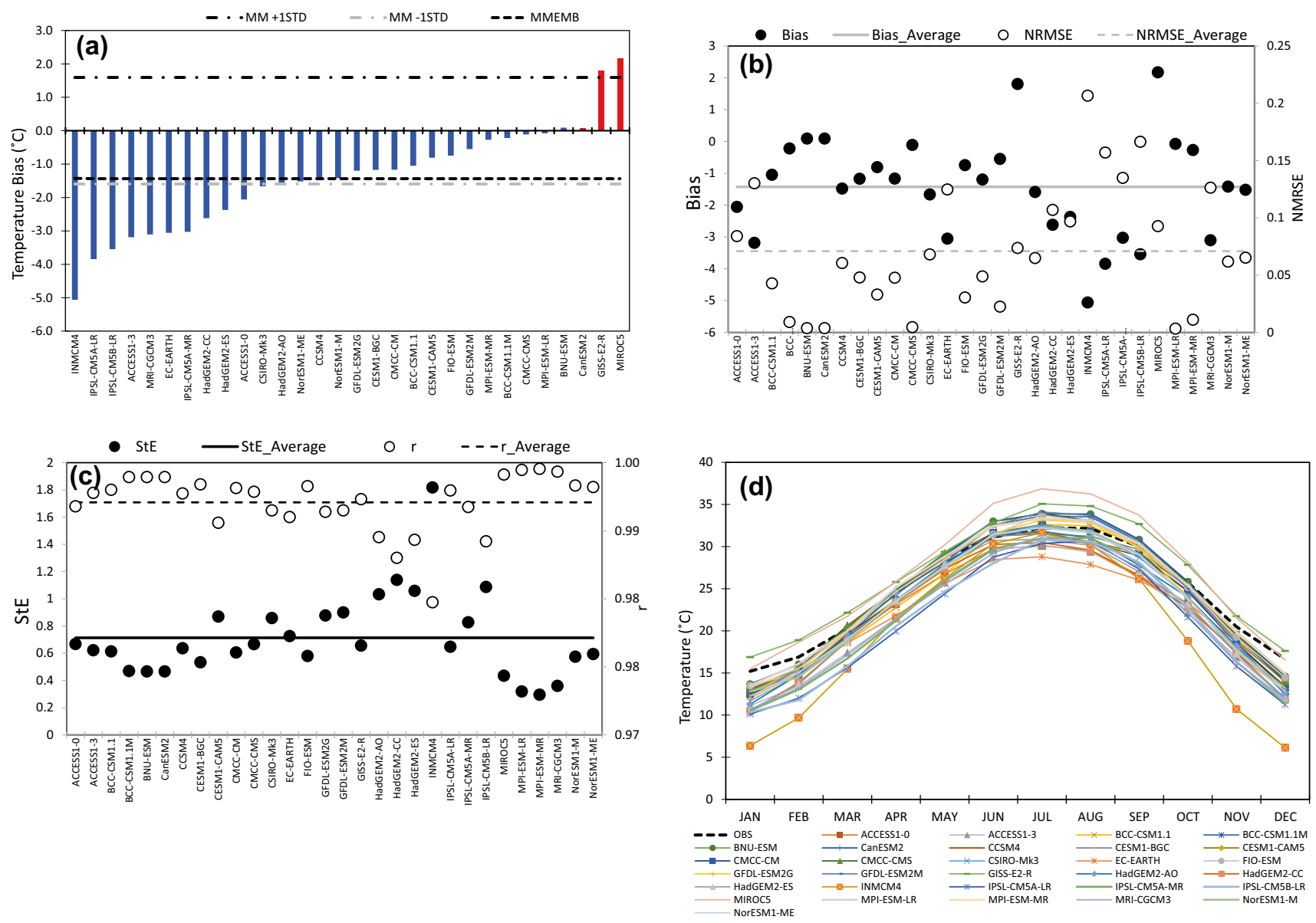

Fig. 1 CMIP5 models (listed in Table 1) simulated temperature with respect to the station observation a Bias, b Bias and NRMSE, c StE and $r$, and $\mathbf{d}$ patterns. The CMIP5 models data are extracted at station nearest coordinates and averaged over 27 locations for the period 1978-2005. The dash-dotted lines in plot (a) show multimodel mean \pm 1 standard deviation. The multimodel ensemble mean bias is

shown by the dashed line. The red (blue) colors are adopted to indicate the warm (cold) CMIP5 models over the Arabian Peninsula. In plots (b) and (c), the horizontal dashed and solid lines indicate average values of respective parameters. In plot (d), the observation is shown by black dashed line. The unit is ${ }^{\circ} \mathrm{C}$ where applicable

future (2006-2099) periods. In addition, the precipitation and temperature data at 27 observational stations across Saudi Arabia for the historical period acquired from the General Authority for Meteorology and Environmental Protection (GAMEP) have been used to assess the CMIP5 models performance for the study region. The observational data from Saudi Arabia are considered representative for the Arabian Peninsula as it covers more than $80 \%$ of the area in the peninsula (Almazroui et al. 2012a, b). The performance of CMIP5 models is examined using Climatic Research Unit (CRU) TS3.23 data (e.g. Figure S1), but for brevity, the results are not shown here (Harris et al. 2014). The future precipitation and temperature projections are

examined for the medium (RCP4.5) and high (RCP8.5) emission scenarios.

Prior to the analysis, we re-gridded the CMIP5 model outputs to a uniform horizontal resolution of a $1^{\circ} \times 1^{\circ}$ grid using bilinear technique. For each CMIP5 model, the performance is examined in simulation of precipitation and temperature over the peninsula. For this purpose, we extracted the model's data for the grid points which correspond to the station locations. For the present climate, the model bias (simulation data minus observation), NRMSE (normalized root mean square error), StE (standard error), correlation coefficient $(r)$, and patterns of simulated precipitation and temperature over the Peninsula are examined with reference 

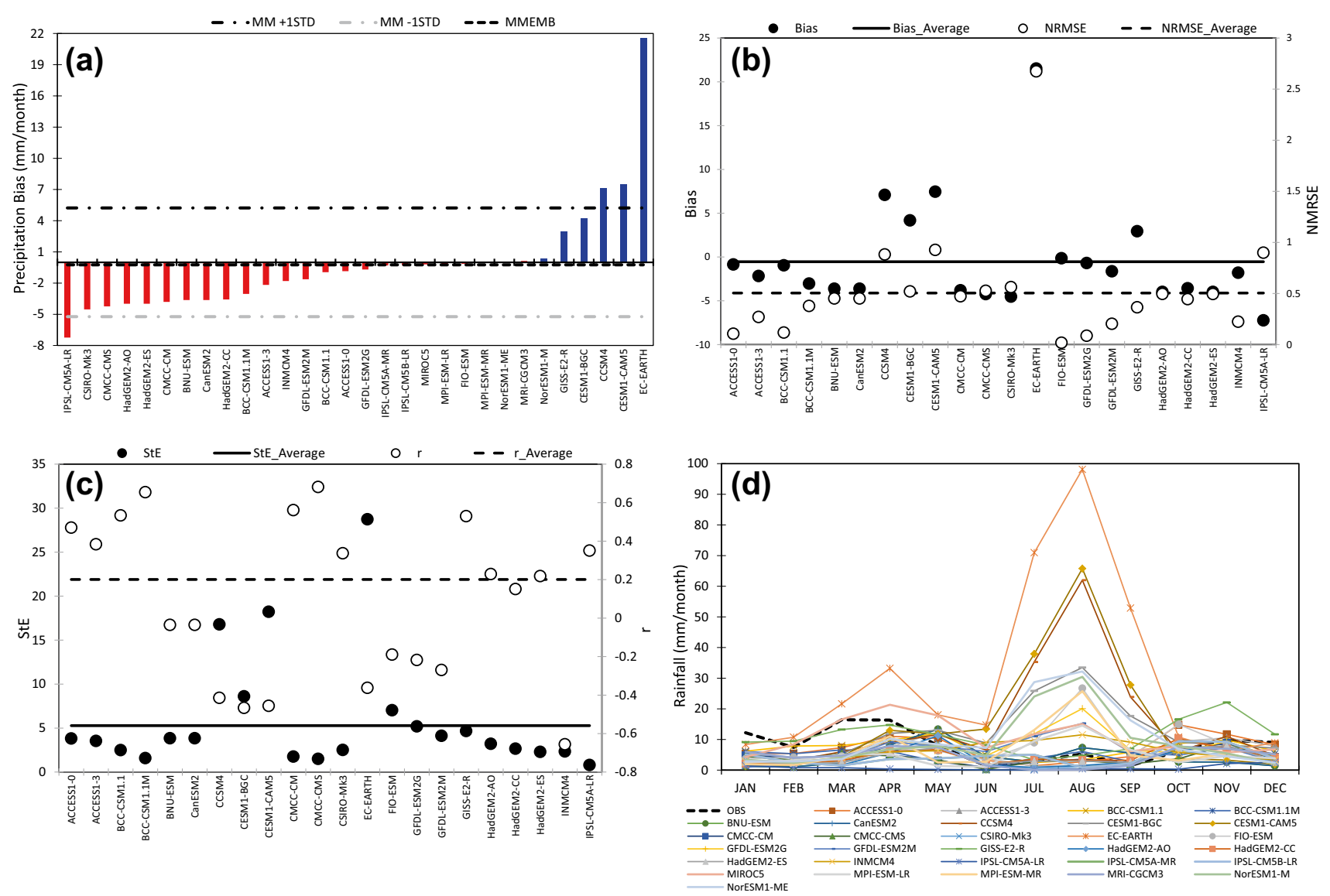

Fig. 2 CMIP5 models (listed in Table 1) simulated precipitation with respect to the station observation: a Bias, b Bias and NRMSE, c StE and r, and $\mathbf{d}$ patterns. The CMIP5 models data are extracted at station nearest coordinates and averaged over 27 locations for the period 1978-2005. The dash-dotted lines in plot (a) show multimodel mean \pm 1 standard deviation. The multimodel ensemble mean bias is

shown by the dashed line. The red (blue) colors are adopted to indicate the dry (wet) CMIP5 models over the Arabian Peninsula. In plots (b) and (c), the horizontal dashed and solid lines indicate average values of respective parameters. In plot (d), the observation is shown by black dashed line. The unit is $\mathrm{mm} / \mathrm{month}$ where applicable

to observations. Based on our analysis following Almazroui et al. (2017b), the CMIP5 models are categorize into three groups, analyzed 30 CMIP5 models, selected CMIP5 models and best-performing CMIP5 models (see the next section). In the second step, we computed the multimodel ensemble means (MMEs) for the above three categories of models. The MMEs are generally preferred over any single model simulation (IPCC 2001). The previous studies (e.g., Weigel et al. 2008; Pincus et al. 2008) noticed that climate projections based on single model simulation are generally not suitable for decision-making purposes. On the other hand, the climate projections based on the MMEs are more suitable, because they contain information from all participating

models. In the present study, we used simple model averaging ensemble method where each model has the same weight in the multimodel projection.

In the next step, the future projections and their corresponding uncertainties for the near future (2021-2050) and far future (2070-2099) with respect to the present climate (1976-2005) are computed for (i) all 30 CMIP5 models ensemble (AME), (ii) selected CMIP5 models ensemble (SME), and (iii) best-performing CMIP5 models ensemble (BME). The robustness of the future signals for three ensembles is examined by investigating the direction of climate change signal in all participating models (Almazroui et al. 2016; Heansler et al. 2013a, b). 
Following Kendall (1976), the significance of the precipitation and temperature trends in the 21 st century simulations is assessed. Following the previous studies (e.g. Di et al. 2015), we used the inter-model standard deviation (STD) and range as metrics to quantify the uncertainty in projected temperature and precipitation. Note that we used data only from the land pixels in this analysis, because surface observations are used for the assessment of models performances.

\section{Results and Discussion}

\subsection{Classification of the CMIP5 Models}

Before assessing the climate change signals, it is important to examine the performance of individual models over a particular region. If the models cannot reasonably simulate the historical and present climate conditions, how much we can trust the future climate projections (Zhao et al. 2015; Watterson et al. 2013). We, therefore, first accessed the CMIP5 models performance over the peninsula against the surface observations for the present climate and grouped them into three main categories (Table 2).

\subsubsection{Assessment of Simulated Temperature in the Present Climate}

To assess the best-performing CMIP5 models suitable for temperature simulation over the peninsula, bias, NRMSE, StE, r, and patterns of simulated temperature for each model involved in this study are analyzed (see Table 1). The models with bias, NRMSE, and StE (r) values close to the observations are the candidates for well-performing models. The models with biases (pattern) within $\pm 1 \sigma$ (observation $\pm 0.5 \sigma$ ) are considered for the second and third categories. Here, " $\sigma$ " represents the multimodel standard deviation. The simulated temperature bias with respect to the surface observation indicates that 18 (12) models fall within (out of) bias $\pm 1 \sigma$ (Fig. 1a). The bias is small (within $\pm 0.3{ }^{\circ} \mathrm{C}$ ) in six models (namely MPI-ESM-MR, BCC-CSM1.1 M, CMCC-CMS, MPIESM-LR, BNU-ESM, and CanESM2), while it is large (larger than $\pm 3{ }^{\circ} \mathrm{C}$ ) for seven models (namely NMCM4, IPSL-CM5A-LR, IPSL-CM5B-LR, ACCESS1-3, MRICGCM3, EC-EARTH, and IPSL-CM5A-MR). The 18 models simulating bias within $\pm 1 \sigma$ are considered as the best-performing models (CT, 2nd column in Table 2). The bias below average (from all 30 models) indicates that 15 models are best-performing candidates in the simulation of temperature (Fig. 1b). Hence, these 15 CMIP5 models are the best-performing candidates (CT, 3rd column in Table 2). Figure $1 \mathrm{~b}$ also infers that 18 models are the bestperforming candidates in NRMS analysis; however, some of them differ for bias analyses (4th column in Table 2). The StE analysis indicates that 19 models are the best-performing candidates (Fig. 1c). Again, common and uncommon models with other statistical measures are found (5th column, Table 2). Figure $1 \mathrm{c}$ indicates that there are 12 models for which the correlation is below the multimodel mean (6th column in Table 2). Taking the pattern within observation $\pm 0.5 \sigma$ (because all model patterns fall within observation $\pm 1 \sigma$ ) and at least common three statistical measures out of four (bias, Average_bias NRMSE, StE, and $r$ ), the temperature models are selected. There are 15 models with patterns within observation $\pm 0.5 \sigma(\mathrm{CT}, 7$ th column in Table 2) out of which 14 are the temperature selected models ( $\mathrm{T}, 8$ th column in Table 2).

\subsubsection{Assessment of Simulated Precipitation in the Present Climate}

The 30 CMIP5 models are assessed to identify the bestperforming models in the simulation of precipitation the peninsula based on statistical measures bias, NRMSE, $\mathrm{StE}, \mathrm{r}$, and patterns. The model precipitation bias with respect to the surface observation indicates that 26 (4) models fall within (out of) bias $\pm 1 \sigma$ (Fig. 2a), where " $\sigma$ " represents the multimodel standard deviation. The bias is small (within $\pm 1 \mathrm{~mm} /$ month) in 12 models (namely BCC-CSM1.1, ACCESS1-0, GFDL-ESM2G, IPSLCM5A-MR, IPSL-CM5B-LR, MIROC5, MPI-ESM-LR, FIO-ESM, MPI-ESM-MR, NorESM1-ME, MRI-CGCM3, and NorESM1-M), while it is large (larger than $\pm 5 \mathrm{~mm} /$ month) in four models (namely IPSL-CM5A-LR, CCSM4, CESM1-CAM5, and EC-EARTH). The 26 CMIP5 models having bias within $\pm 1 \sigma$ are the candidates for bestperforming models (CP, 9th column in Table 2). The bias below of its average indicates that 21 models are candidates for best-performing in the simulation of precipitation (Fig. 2b). The 21 models are the best-performing candidates $(\mathrm{CP}, 10$ th column in Table 2$)$. Figure $2 \mathrm{~b}$ also 

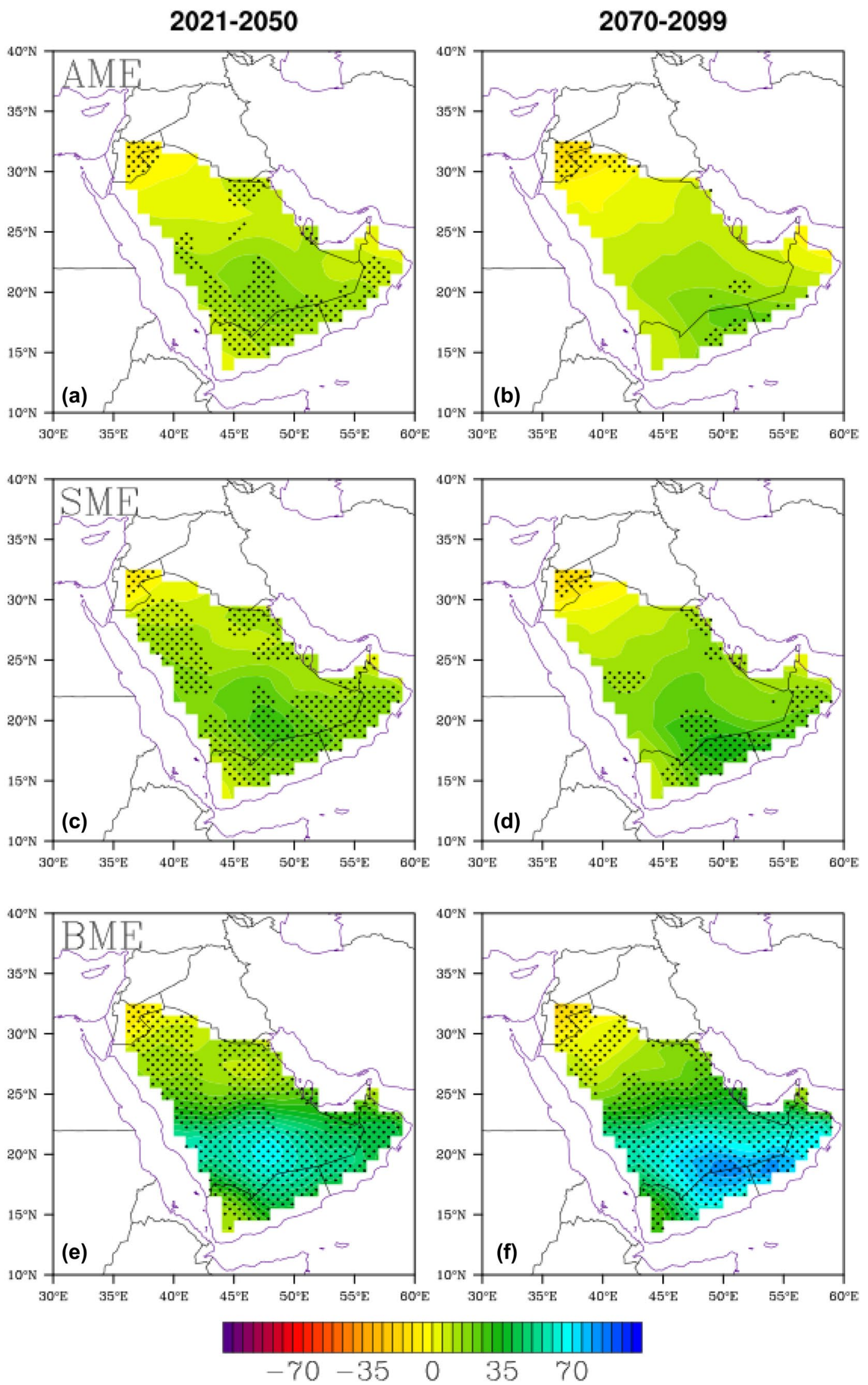

3570 
4Fig. 3 Simulated future changes in precipitation (\%) for RCP4.5 scenarios over the Arabian Peninsula by AME, SME, and BME for near future (2021-2050, left panel) and far future (2070-2099, right panel) with reference to the present climate (1976-2005). The regions where at least $66 \%$ of CMIP5 models agree on sign of change are indicated by the dotted areas

infers that 20 models are the best-performing candidates in NRMSE analysis; however, all of them are common in bias analysis (11th column in Table 2). The StE analysis indicates that 24 models are the best-performing candidates (Fig. 2c). Again, common and uncommon models with bias and NRMSE analyses are found (12th column, Table 2). The correlation analysis shows that 18 models are best-performing candidates (Fig. $2 \mathrm{c}$ and 13th column in Table 2). Taking the pattern within observation nearly $\pm 1 \sigma$ (because exactly within observation $\pm 1 \sigma$ is none) and at least common three statistical measures out of five (bias, average_bias, NRMSE, StE, and r), the precipitation models are selected. There are 13 models showing patterns within observation nearly $\pm 1 \sigma(\mathrm{CP}, 14$ th column in Table 2) which are also the precipitation selected models (P, 15th column in Table 2). Results show that there are 20 selected models ( $\mathrm{S}, 16$ th column in Table 2 ) which are performing well in the simulation of either temperature or precipitation, while eight of them are common for both parameters $\left(S^{*}, 16\right.$ th column in Table 2$)$. These common models are called best-performing models.

\subsection{Future Precipitation Change}

The climate of the Arabian Peninsula is in semi-arid and arid category; therefore, the amount of precipitation in the peninsula is low in amount. The projected future precipitation change in the Arabian Peninsula for three ensembles (i.e., AME, SME, and BSME) is shown in Fig. 3 and Fig. 4 for the emission scenario RCP4.5 and RCP8.5, respectively. For both scenarios, the projected precipitation change is highest (lowest) for the BME (AME), while for the SME, it lies between these two extremes. For all three ensembles, the future precipitation shows a reduction (enhancement) over the northwestern (southern) part of the Arabian Peninsula. In the case of AME, there is a small spatial area where the sign of change agrees for more than $66 \%$ of the contributing models. This spatial area increases for the SME and BME. Although, the precipitation change for AME, SME, and BSME shows a nearly similar spatial pattern, the magnitude of change varies widely between the three set of ensembles.
In the case of RCP4.5 scenario, the AME reveals future precipitation change that lies between -30 and $+35 \%$ for both the near future and far future periods (Fig. 3a, b). The SME also shows a similar precipitation change $(-30$ to $+35 \%)$ for both the near future and far future periods. However, the spatial area coverage in this case slightly differs from the AME case (Fig. 3c, d). In the case of BME (Fig. 3e, f), the projected precipitation shows a higher change ranging from - 30 to $70 \%$ for the near future (2021-2050) and - 30 to more than $100 \%$ for the far future (2070-2099) period. It is interesting that the spatial area covered with positive precipitation change has increased in size for the BME compared to the AME and SME.

In the case of RCP8.5 emission scenario (Fig. 4), a larger part of the peninsula shows positive change in future precipitation with reference to the present climate for all three ensembles. The spatial pattern of the change in future precipitation under RCP8.5 is nearly similar to that shown in case of RCP4.5 (Fig. 3); however, the projections show more positive change in precipitation under the RCP8.5 in all three ensembles cases compared to the RCP4.5. Again, under RCP8.5, the precipitation change is larger in the BME compared to AME and SME. Using CMIP3 models ensembles, Almazroui et al. (2016) showed that the precipitation in future climate over the Peninsula enhances (reduces) for the southern and adjacent southeastern (northwestern) areas. In the present study, the projected changes based on three multimodel ensembles (i.e., AME, SME, and BME) show that a larger part of the peninsula will receive surplus precipitation in the 21 st century.

Figure 5 shows the changes in annual mean precipitation over the peninsula as compared to the present climate (1976-2005). The annual mean precipitation reveals strong inter-annual variability for both RCPs (Fig. 5). The interannual variability is larger for the BME compared to AME and SME. This is simply because the number of models in the BME is smaller and the variations in the individual models are, therefore, not completely cancelled out. On average, the AME revealed a significantly (99\% level, Mann-Kendall trend test) rising trends in precipitation over the Arabian Peninsula [0.17\% (19.9\%)/100 year for the RCP4.5 (RCP8.5) scenario]. For SME and BME, these values are 1.82\% $(27.5 \%) / 100$ year and $13.7 \%(62.5 \%) / 100$ year, respectively (Table 3).

We also examined the change in future precipitation over the northern $\left(25^{\circ} \mathrm{N}-33^{\circ} \mathrm{N} ; 36^{\circ} \mathrm{E}-52^{\circ} \mathrm{E}\right)$ and southern $\left(13^{\circ} \mathrm{N}-25^{\circ} \mathrm{N} ; 40^{\circ} \mathrm{E}-60^{\circ} \mathrm{E}\right)$ Arabian Peninsula (Fig. 6). In this case, we first computed change in the precipitation over each 
2021-2050
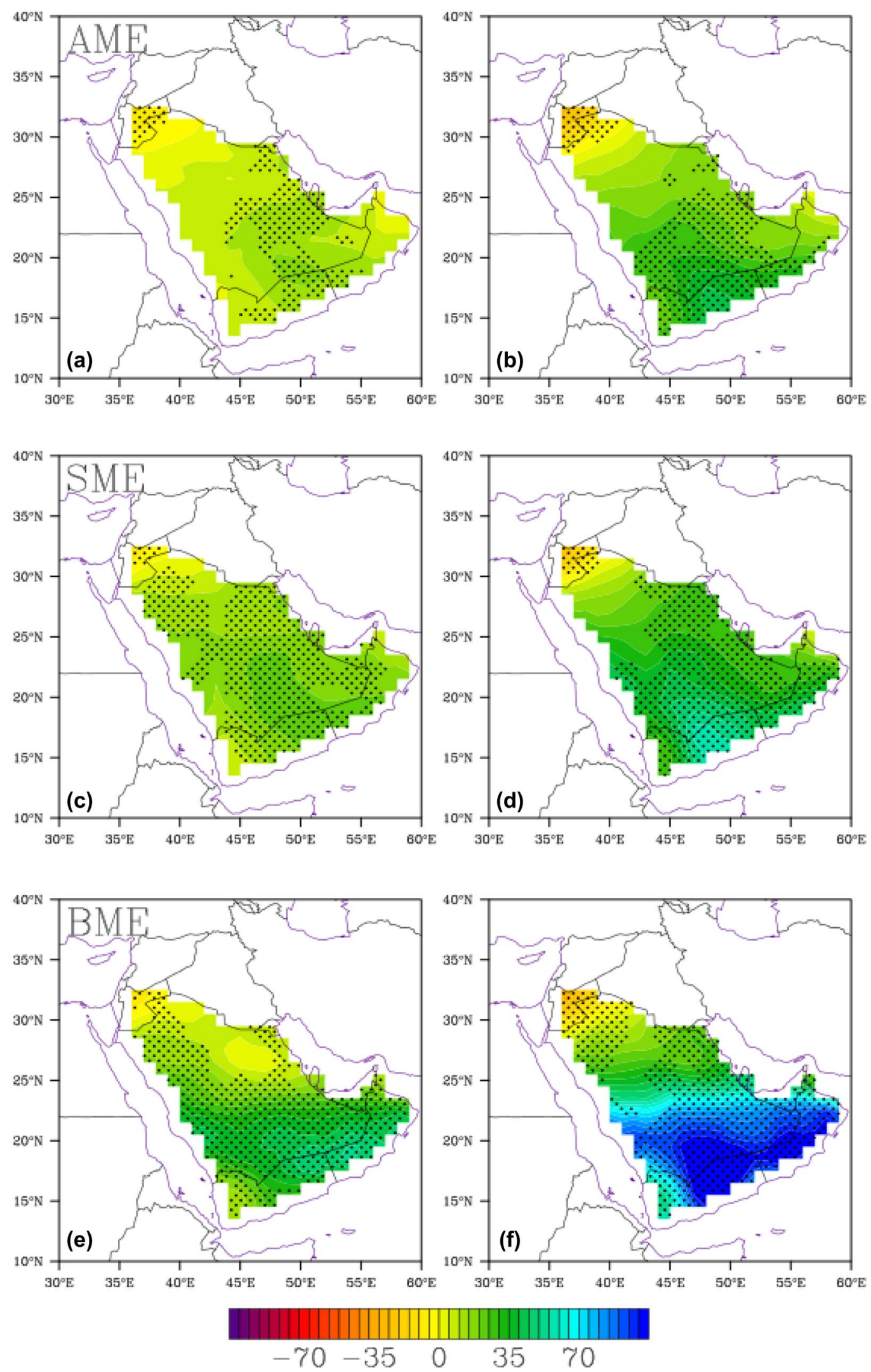

3570

Fig. 4 Same as Fig. 3 except the future changes are for RCP8.5 scenario 


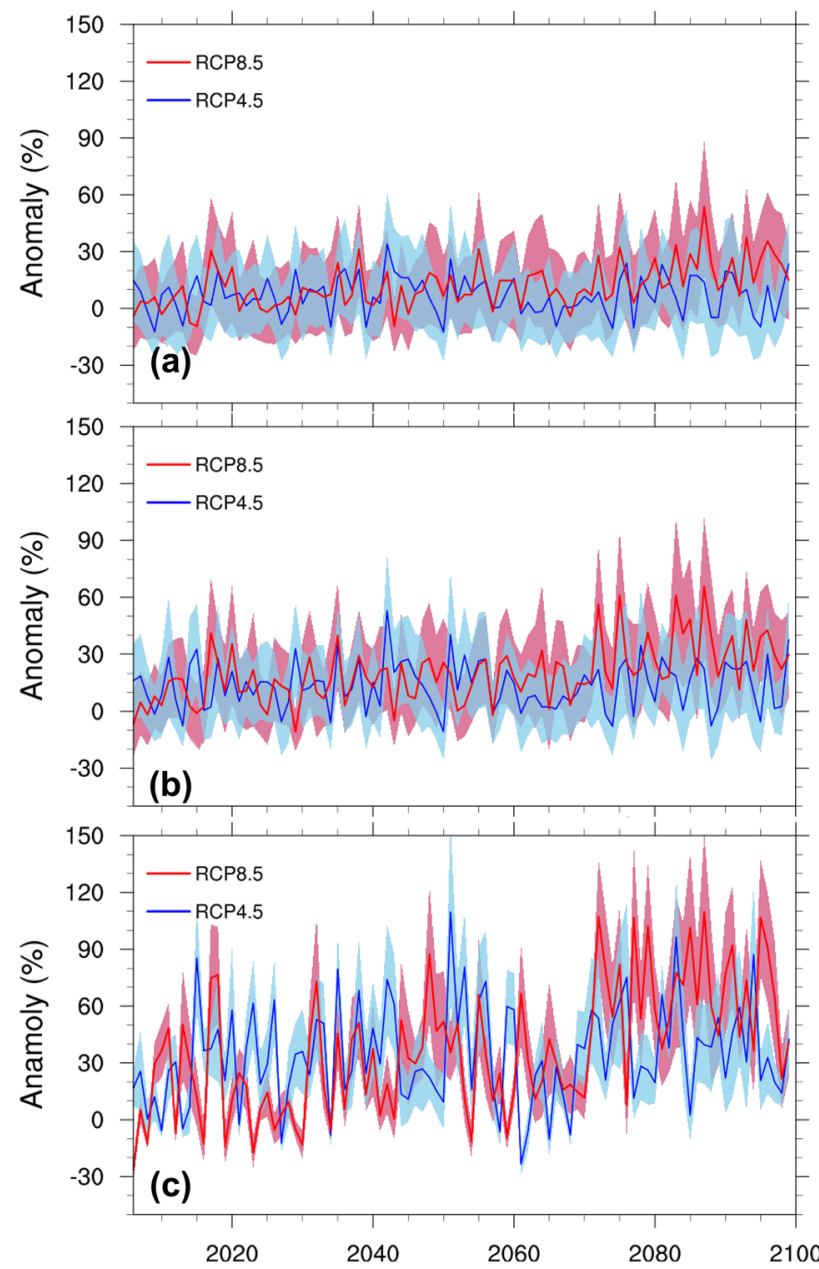

Fig. 5 a Simulated annual mean precipitation anomalies (\%) averaged over the Arabian Peninsula, relative to 1976-2005 for RCP4.5 (blue) and RCP8.5 (red) scenarios from the AME (solid line) with \pm one inter-model standard deviation (color shading). The \pm one standard deviation for RCP4.5 and RCP8.5 scenarios are shown by light sky blue and violet red colors. b, c same as (a) except showing changes for SME and BME grid cell within the analysis domain. We then constructed a sample consisting of change values from each grid cell. For both RCPs, the BME shows larger spatial area showing positive change in precipitation over both the northern and southern Arabian Peninsula in the near future and far future periods. This is evident from the widening of the distribution in the BME compared to the AME and SME. The increase in spatial area with positive precipitation change in the BME might be associated with increase in precipitation extremes over this region. Further studies are needed to examine this issue in detail.

\subsection{Future Temperature Change}

The Arabian Peninsula has relatively high annual mean temperature. The gradual rise in temperature is noticed over the peninsula using average from all models during the 21 st century (e.g., Almazroui et al. 2017a, b). Figures 7 and 8 show the future changes in temperature as compared to the present climate (1976-2005) over the Arabian Peninsula for three multimodel ensemble means (i.e., AME, SME, and BME) under two emission scenarios RCP4.5 and RCP8.5. The spatial pattern of the projected temperature over the peninsula resembles to those obtained by Almazroui et al. (2017a). In the case of RCP4.5, the BME shows more increase in the future temperature as compared to the AME and SME (Fig. 7). In all three ensembles, the projected temperature shows larger changes towards the end of the 21st century. The AME reveals a spatial change in temperature over the Arabian Peninsula that varies from 1 to $1.8{ }^{\circ} \mathrm{C}\left(2\right.$ to $\left.2.8{ }^{\circ} \mathrm{C}\right)$ in the near future (far future) period. Similarly, SME shows a spatial change in temperature between 1 and $1.8^{\circ} \mathrm{C}$ (2.2 to $3{ }^{\circ} \mathrm{C}$ ), while the BME shows a temperature change between 1 and $1.8{ }^{\circ} \mathrm{C}\left(2.2\right.$ to $\left.3.2{ }^{\circ} \mathrm{C}\right)$ in the near future (far future) periods.

For the RCP8.5 emission scenario, the changes in projected temperature are higher than the changes in RCP4.5

Table 3 Simulated Temperature and Precipitation trends AME, SME, and BME over the Arabian Peninsula during 21st century. The trends in temperature are significant at $99 \%$ confidence level based on Mann-Kendall trend test

\begin{tabular}{llllcrc}
\hline & \multicolumn{1}{c}{ Temperature trend $\left({ }^{\circ} \mathrm{C} / 100\right.$ year $)$} & \multicolumn{3}{c}{ Precipitation trend $(\% / 100$ year $)$} \\
\hline RCP4.5 & AME & SME & BME & AME & SME & 1.82 \\
RCP8.5 & 2.29 & 2.63 & 2.59 & 0.17 & 13.9 \\
\hline
\end{tabular}




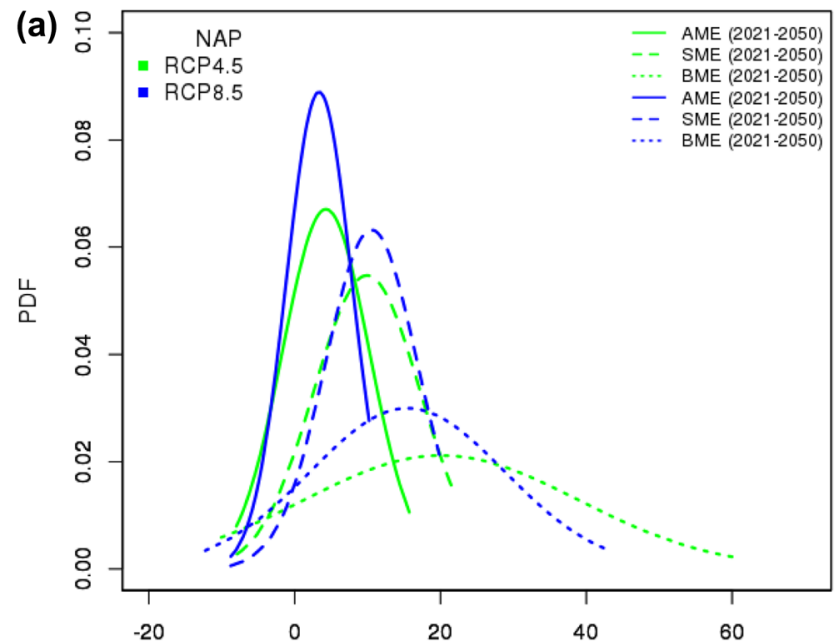

(c)

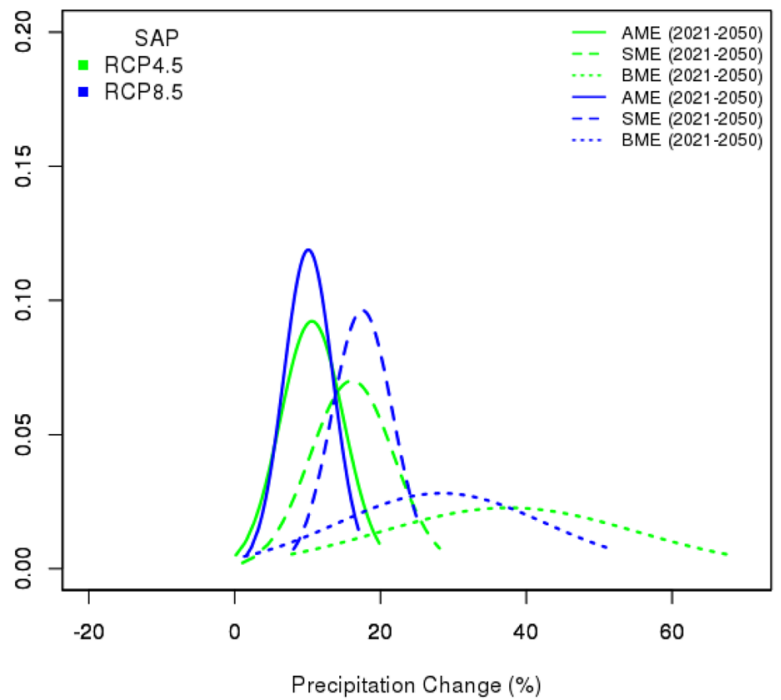

Fig. 6 Future precipitation changes in the northern (a, b) and southern (c, d) Arabian Peninsula. The solid, dashed, and dotted lines show future changes for AME, SME, and BME. The green and blue colors

(Fig. 8). The AME reveals future temperature increase over the Arabian Peninsula that varies spatially from 1 to $2{ }^{\circ} \mathrm{C}(3.4$ to $5{ }^{\circ} \mathrm{C}$ ) in the near future (far future) period. Similarly, SME reveal a temperature change that varies spatially from 1 to $2.4{ }^{\circ} \mathrm{C}\left(3.4\right.$ to $\left.5.2{ }^{\circ} \mathrm{C}\right)$, while the BME shows a temperature change from 1 to $2.4{ }^{\circ} \mathrm{C}\left(3.4\right.$ to $\left.5.8{ }^{\circ} \mathrm{C}\right)$ over the Arabian

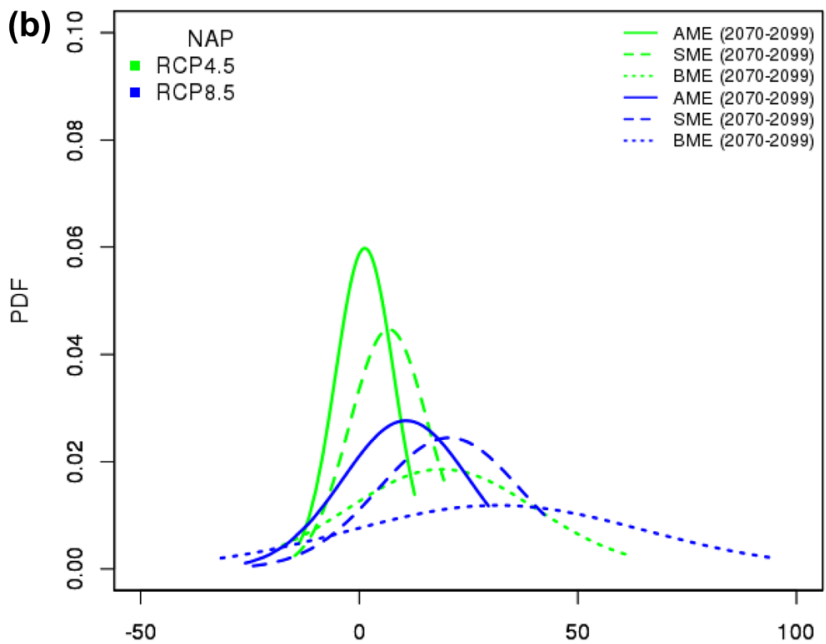

(d)

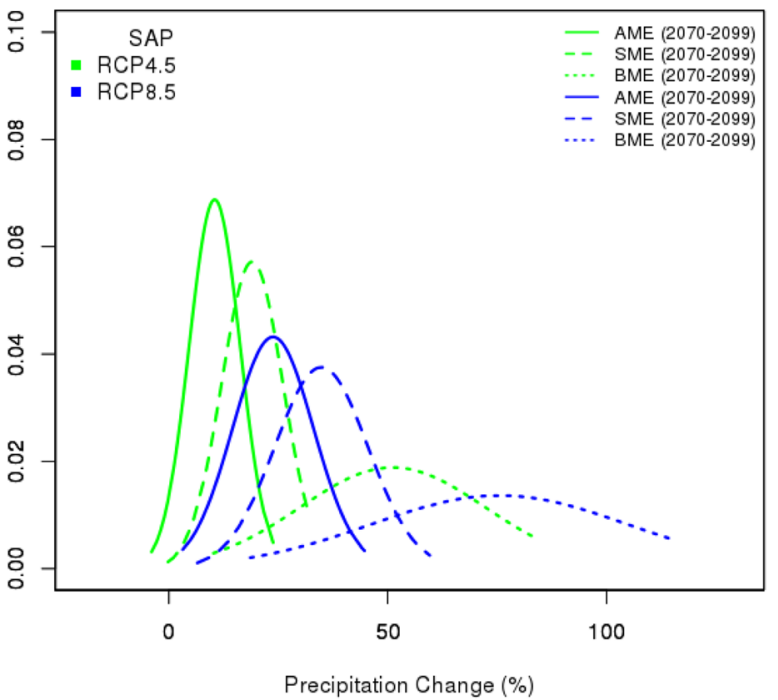

show the change for RCP 4.5 and RCP8.5 scenario, respectively. The left (right) panels show future changes for mid-century (end-century) periods

Peninsula for near future (far future) period. For both RCPs, the projected future temperature shows larger change over the central part of the Arabian Peninsula in all three ensembles. Furthermore, the projected temperature changes over the Arabian Peninsula are more pronounced in the BME as compared to the AME and SME. 
Over the peninsula, a continuous increase in temperature is shown by the multimodel ensembles AME, SME, and BME during the 21st century for both RCP4.5 and 8.5 scenarios (Fig. 9). In all three cases, the projected temperature under the two scenarios reveals small difference in the early half of the 21 st century. The gradual rise in temperature is noticed with the integration of time. Moreover, the projected temperature shows small changes for the RCP4.5 scenario as compared to the RCP8.5 during the full integration period. On average, the AME reveals that temperature over the Arabian Peninsula will increase by 2.28 (5.53) ${ }^{\circ} \mathrm{C} / 100$ year for the RCP4.5 (RCP8.5) scenario. For SME and BME, these values are 2.63 (6.07) ${ }^{\circ} \mathrm{C} / 100$ year and 2.59 (6.04) ${ }^{\circ} \mathrm{C} / 100$ year, respectively (Table 3). The above trends in temperature are significant (99\% level, Mann-Kendall trend test).

The change in future temperature over the northern $\left(25^{\circ} \mathrm{N}-33^{\circ} \mathrm{N} ; 36^{\circ} \mathrm{E}-52^{\circ} \mathrm{E}\right)$ and southern $\left(13^{\circ} \mathrm{N}-25^{\circ} \mathrm{N}\right.$; $40^{\circ} \mathrm{E}-60^{\circ} \mathrm{E}$ ) Arabian Peninsula are also examined (Fig. 10). In case of both RCP4.5 and RCP8.5 emission scenarios in the near future (2021-2050) and far feature (2070-2099) periods, the three ensembles show positive change in temperature over both northern and southern Arabian Peninsula. For both RCPs, the difference between AME, SME, and $\mathrm{BME}$ is marginal in the near future (2021-2050), relative to the present climate (1976-2005) (Figs. 7, 8, 10). However, the difference in temperature is larger in the far future period as compared to the present climate. In the future climate, the BME shows larger increase in temperature in the northern and southern areas of the peninsula as compared to the AME and SME. This is especially evident in case of high RCP8.5 scenario. The results of AME resembles to a previous study by Almzroui et al. (2017a).

\subsection{Uncertainties Associated with Future Projections of Precipitation and Temperature}

To examine the uncertainties related to the future projections revealed by three different categories of multimodel ensembles presented above (i.e., AME, SME, and BME) is one of the aims of this study. Although the multimodel ensemble-based projections are not free from uncertainties, the policy makers are generally interested in climate projection for long-term planning. The mean precipitation with \pm one standard deviation (STD) and inter-model range for the AME, SME, and BME is shown in Figs. 5 and $11 \mathrm{~b}$. As precipitation is highly variable over the Arabian Peninsula and the annual precipitation amount is very low, the uncertainties associated with precipitation are larger during both near future and far future periods (Fig. 9b). The BME shows enhanced future mean precipitation over the peninsula compared to the AME and SME (Fig. 9b). For the near future period, the differences in the uncertainties associated with precipitation projections for the three ensembles are marginal (Fig. 9b). During the period near future, the mean of the annual precipitation is supposed to be increased by $9.68 \pm 20 \%(8.27 \pm 36 \%), 11.86 \pm 20 \%(8.42 \pm 26 \%)$, and $21.62 \pm 20 \%(13.31 \pm 20 \%)$ for the AME, SME, and BME, under RCP4.5 (RCP8.5) scenario, respectively, relative to the present climate (1976-2005). The inter-model ranges from -13 to $116 \%$ ( -33 to $79 \%$ ), -13 to $116 \%$ ( -21 to $79 \%$ ), and -12 to $116 \%$ (-13 to $79 \%$ ) for the AME, SME, and BME under RCP4.5 (RCP8.5), respectively, relative to the present climate. During the far future, the mean of the annual precipitation is supposed to be increased by $8.27 \pm 20 \%(27.34 \pm 50 \%), 12.57 \pm 40 \%(30.18 \pm 55 \%)$, and $25.96 \pm 30 \%(45.19 \pm 50 \%)$ for the AME, SME, and BME, under RCP4.5 (RCP8.5) scenario, respectively. The inter-model ranges from -33 to $145 \%$ ( -30 to $200 \%$ ), -33 to $145 \%$ ( -30 to $200 \%$ ), and -8 to $145 \%$ ( -5 to $200 \%$ ) for the AME, SME, and BME under RCP4.5 (RCP8.5), respectively (Fig. 9b). The uncertainties associated with precipitation projections increase with integration of time towards the end of 21st century. Furthermore, the difference between the RCP4.5 and RCP8.5 emission scenario-based precipitation projections is larger towards the end of 21 st century.

The mean temperature change with \pm one standard deviation (STD) and inter-model range for the AME, SME, and BME are shown in Figs. 9 and 11a. In all cases, the temperature increases continuously from 2006 under the RCP4.5 and RCP8.5 emission scenarios, however, largest warming under RCP8.5 towards the end of 21st century (Fig. 9).

The \pm one STD and inter-model range show smaller spread in case of BME (Figs. 9c, 11a) compared to the 
2021-2050
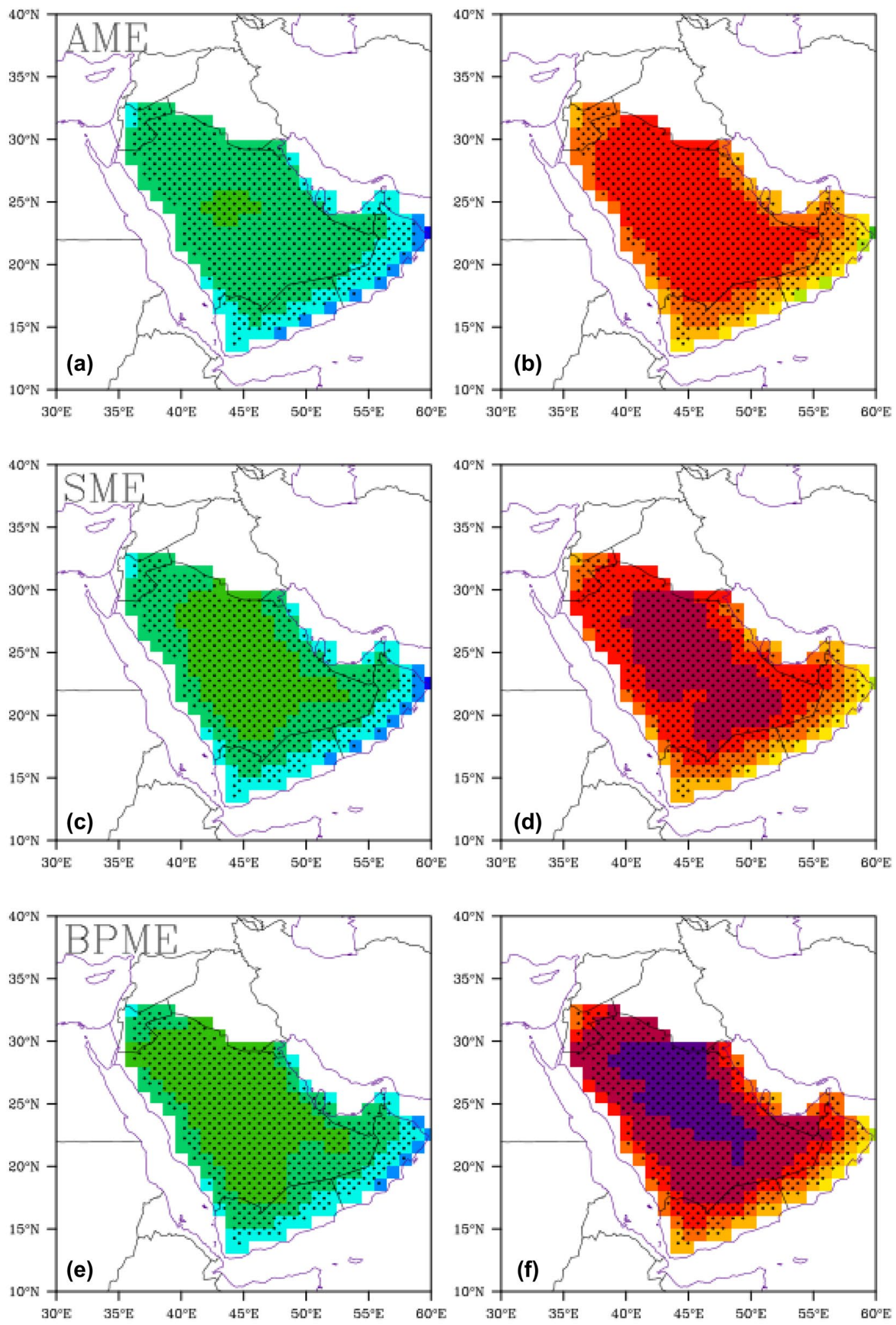

$$
10
$$


4Fig. 7 Simulated future changes in temperature (units: ${ }^{\circ} \mathrm{C}$ ) for $\mathrm{RCP} 4.5$ scenarios over the Arabian Peninsula by AME, SME, and BME for near future (2021-2050, left panel) and far future (2070-2099, right panel) with reference to the present climate (1976-2005). The regions where at least $66 \%$ of CMIP5 models agree on sign of change are indicated by the dotted areas

AME and SME (Figs. 9a, b, 11a). The two emission scenarios show increase in uncertainty with the increase in time. During the near future, the mean of the annual temperature is supposed to be increased by $1.47 \pm 0.35{ }^{\circ} \mathrm{C}$ $\left(1.77 \pm 0.35{ }^{\circ} \mathrm{C}\right), 1.55 \pm 0.31{ }^{\circ} \mathrm{C}\left(1.83 \pm 0.33{ }^{\circ} \mathrm{C}\right)$, and $1.55 \pm 0.25{ }^{\circ} \mathrm{C}\left(1.88 \pm 0.27{ }^{\circ} \mathrm{C}\right)$ for the AME, SME, and BME, under RCP4.5 (RCP8.5) scenario, respectively. The inter-model ranges from 0.58 to $2.08{ }^{\circ} \mathrm{C}\left(0.92\right.$ to $\left.2.55{ }^{\circ} \mathrm{C}\right)$, 0.96 to $2.08{ }^{\circ} \mathrm{C}\left(1.37\right.$ to $\left.2.55{ }^{\circ} \mathrm{C}\right)$, and 1.19 to $1.99{ }^{\circ} \mathrm{C}(1.55$ to $2.35{ }^{\circ} \mathrm{C}$ ) for the AME, SME, and BME under RCP4.5 (RCP8.5), respectively. During the far future, the annual mean temperature is projected to increase by $2.51 \pm 0.72{ }^{\circ} \mathrm{C}$ $\left(4.87 \pm 0.86{ }^{\circ} \mathrm{C}\right), 2.59 \pm 0.80{ }^{\circ} \mathrm{C}\left(5.04 \pm 0.79{ }^{\circ} \mathrm{C}\right)$, and $2.79 \pm 0.30{ }^{\circ} \mathrm{C}\left(5.26 \pm 0.32{ }^{\circ} \mathrm{C}\right)$ for the AME, SME, and BME, under RCP4.5 (RCP8.5) scenario, respectively. The inter-model ranges from 1.10 to $3.69{ }^{\circ} \mathrm{C}\left(3.49\right.$ to $\left.6.34{ }^{\circ} \mathrm{C}\right)$, 1.10 to $3.69{ }^{\circ} \mathrm{C}\left(3.76\right.$ to $6.34{ }^{\circ} \mathrm{C}$ ), and 2.11 to $3.22{ }^{\circ} \mathrm{C}$ (4.36 to $5.95{ }^{\circ} \mathrm{C}$ ) for the AME, SME, and BME under RCP4.5 (RCP8.5), respectively. The above results indicate that the model spread and uncertainties range associated with temperature projections is reduced remarkably in the case of BME as compared to the AME and SME (Figs. 9, 11a). The results further suggest that selected models may provide more reasonable projections that can be used with relatively high confidence for future policy planning purposes.

\section{Summary and Conclusions}

This current study examined the changes in precipitation and temperature and their corresponding uncertainties over the Arabian Peninsula in the 21st century under RCP4.5 and RCP8.5 emission scenarios using three different multimodel ensembles from CMIP5 data set. Analyzing the performance of each model for the present climate, the CMIP5 models are categorized into three groups. The three groups are (i) all CMIP5 models ensemble (AME), (ii) selected CMIP5 models ensemble (SME), and (iii) best-performing CMIP5 models ensemble (BME).

In the 21 st century, the projections show positive change in precipitation over most parts of the peninsula with respect to the present climate (1976-2005). The projected precipitation pattern over the Arabian Peninsula shows a marginal difference between AME, SME, and BME in the near future (2021-2050) period. However, the difference between the three ensemble projected mean precipitation increases with the advancement of time. For the peninsula, the BME shows a large positive change in future precipitation compared to AME and SME. For the far future, the annual precipitation in supposed to be increased by $8.27 \pm 20 \%(27.34 \pm 50 \%), 12.57 \pm 40 \%$ $(30.18 \pm 55 \%)$, and $25.96 \pm 30 \%(45.19 \pm 50 \%)$ for the AME, SME, and BME, under RCP4.5 (RCP8.5) scenario, respectively. In this period, the associated inter-model range for AME, SME, and BME under RCP4.5 (RCP8.5) is -33 to $145 \%$ ( -30 to $200 \%$ ), -33 to $145 \%$ ( -30 to $200 \%$ ), and -8 to $145 \%$ ( -5 to $200 \%$ ), respectively. The projected precipitation shows large inter-annual variability over the Arabian Peninsula in all three multimodel ensembles. The uncertainties in projected precipitation over the Arabian Peninsula are larger and seem less sensitive to the emission scenarios as compared to the temperature projections. The previous studies (e.g., Hawkins and Sutton 2009) showed that the precipitation is either not or less sensitive to the emission scenarios than temperature. In all three multimodel ensembles, the northwestern part of the Arabian Peninsula will receive less precipitation in the future relative to the present climate. The northwestern part of the Arabian Peninsula mainly receives precipitation from the western disturbances that originate in the North Atlantic Ocean and the Mediterranean Sea and travel to the East (Almazroui and Awad 2016). The CMIP5 models show a poleward shift of the mid-latitude jet by $1.1^{\circ}$ over the North Atlantic by the end of 21 st century (Barnes and Polvani 2013). The northward shift in the upper-level jet 
2021-2050
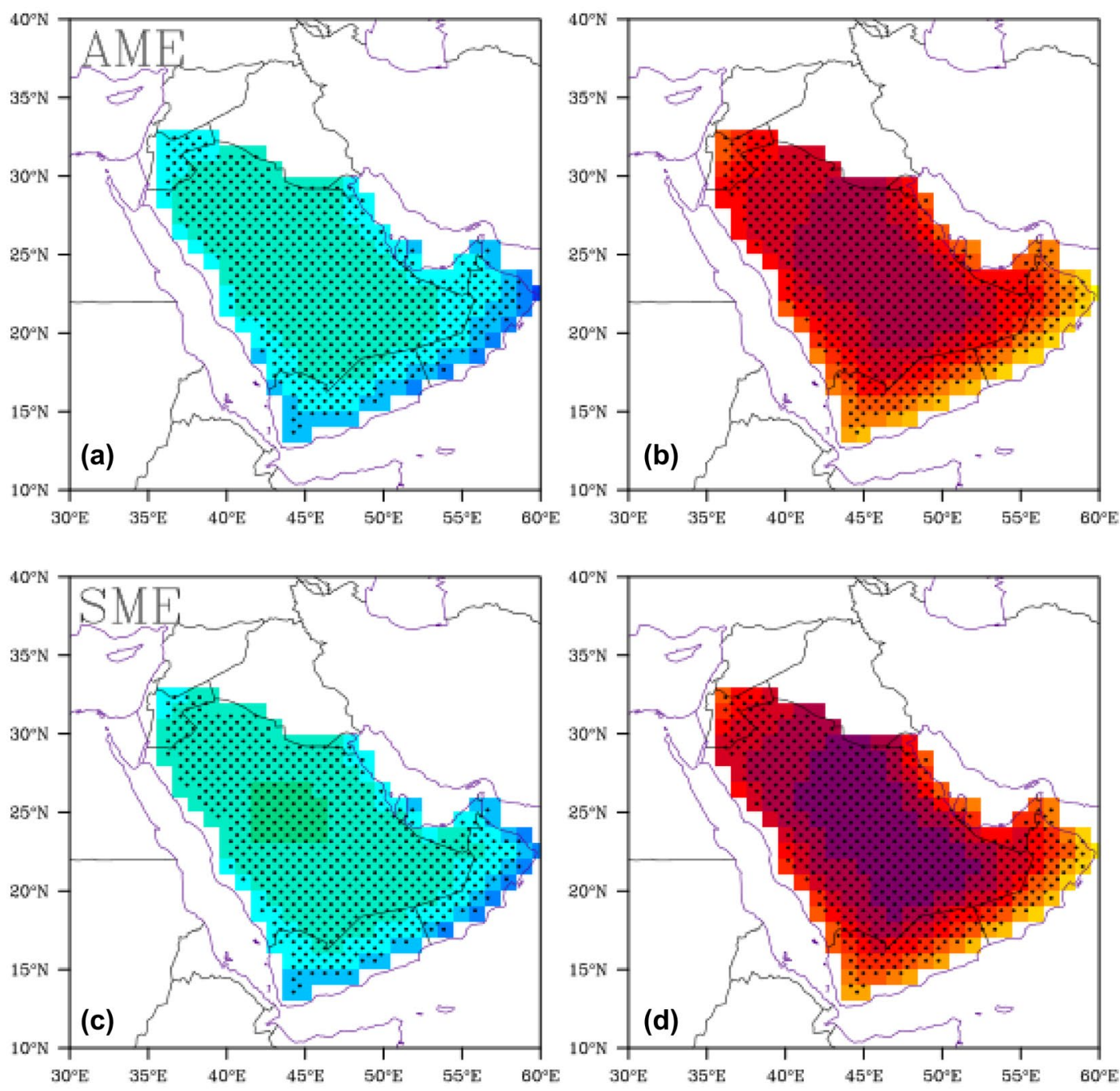
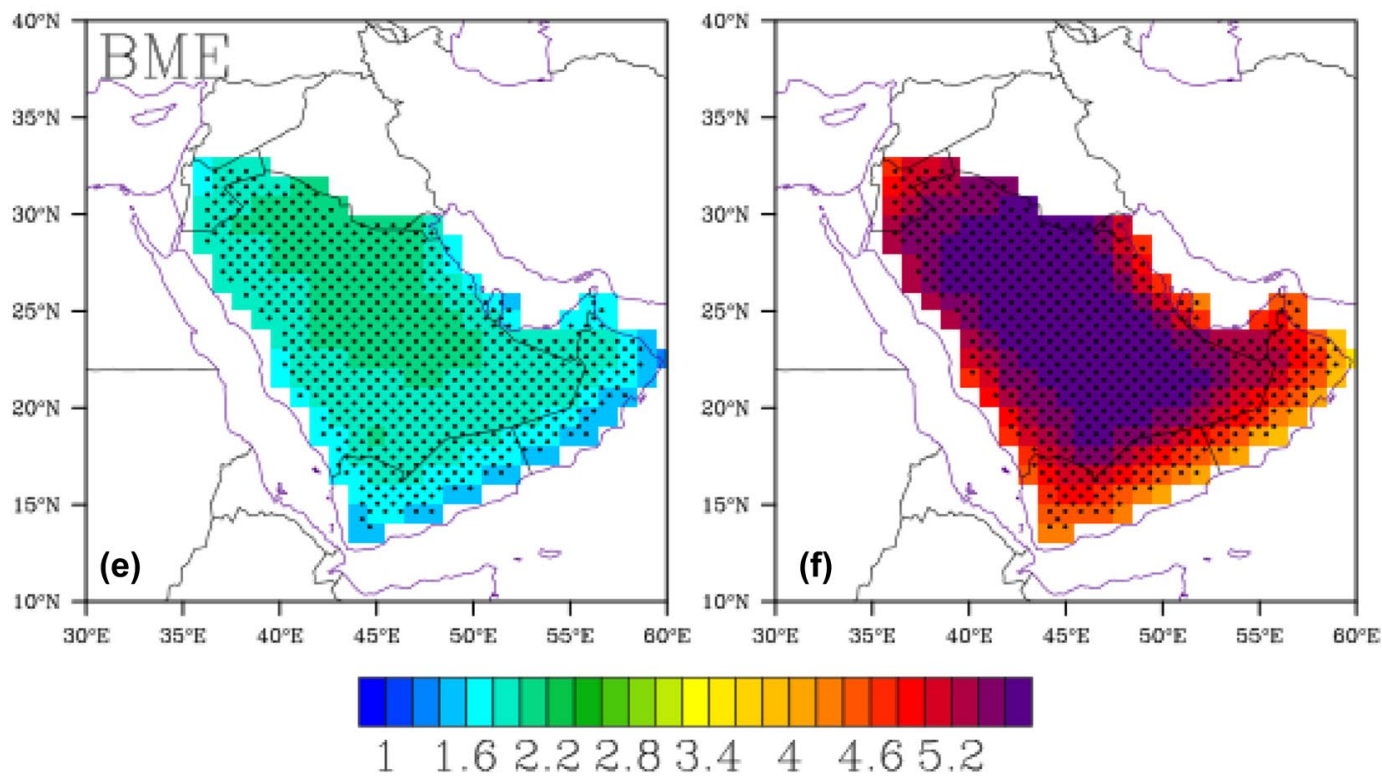

Fig. 8 Same as Fig. 7 except for the future changes are for RCP8.5 scenario 


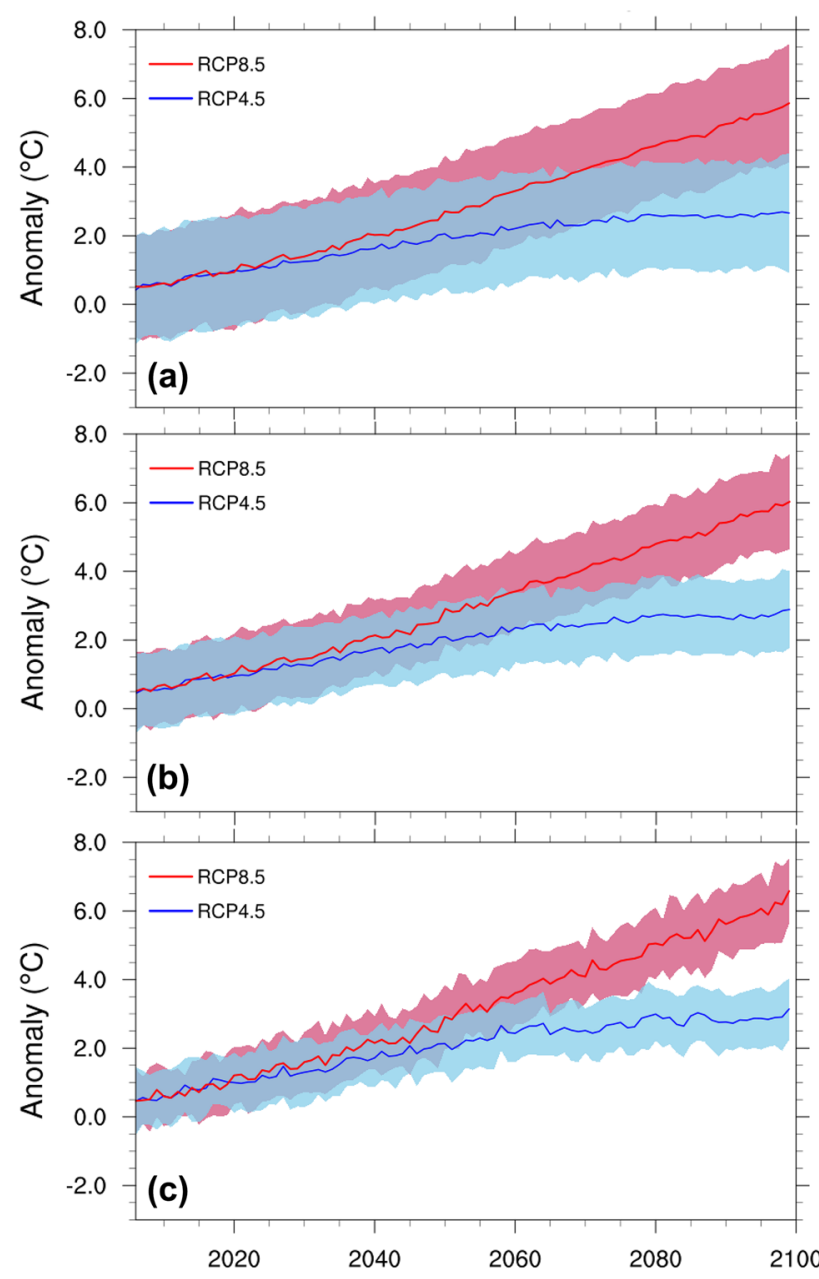

Fig. 9 a Simulated annual mean temperature anomalies (unit: ${ }^{\circ} \mathrm{C}$ ) averaged over the Arabian Peninsula, relative to 1976-2005 for RCP4.5 (blue) and RCP8.5 (red) scenarios from the AME (solid line) with \pm one inter-model standard deviation (color shading). The \pm one standard deviation for RCP4.5 and RCP8.5 scenarios is shown by light sky blue and violet red colors. b, c same as (a) except showing changes for SME and BME may be associated with a reduction in the precipitation by influencing the number of cyclonic systems (Almazroui and Awad 2016) reaching the northwestern part of the Arabian Peninsula.

On the other hand, the southern part of the Peninsula is projected to receive enhanced future precipitation. The southern and eastern parts of the peninsula are influenced mainly by the convection associated with the variation of inter-tropical convergence zone and the South Asian monsoon flow that also intrudes into the southern and eastern parts of the peninsula. This could be associated with enhanced southwesterly monsoon flow in the CMIP5 models projections (Menon et al. 2013). The CMIP5 models also simulate cold bias in sea surface temperature (SST) over the north Arabian Sea (Levine et al. 2013). This cold bias is associated with enhanced low-level moist flow into the Arabian Peninsula (clearly visible in the figures of Levine et al. 2013). It is not yet clear that to what extent the Arabian Sea cold SST bias contributes to the enhancement of future precipitation in the southeastern and southern areas of the peninsula. Further studies are, therefore, needed to explore this issue in detail.

The multimodel ensembles AME, SME, and BME show a gradual rise in over the peninsula in temperature in the future climate. The uncertainties associated with the projected temperature are remarkably reduced in the case of BME. The BME also shows robust amplification in the future mean temperature compared to the AME and SME. For the far future, the temperature is supposed to be raised by $2.51 \pm 0.72{ }^{\circ} \mathrm{C}\left(4.87 \pm 0.86{ }^{\circ} \mathrm{C}\right), 2.59 \pm 0.80{ }^{\circ} \mathrm{C}$ $\left(5.04 \pm 0.79{ }^{\circ} \mathrm{C}\right)$, and $2.79 \pm 0.30{ }^{\circ} \mathrm{C}\left(5.26 \pm 0.32{ }^{\circ} \mathrm{C}\right)$, compared to the present climate (1976-2005) for the AME, SME, and BME, under RCP4.5 (RCP8.5) scenario, respectively. The inter-model range for $\mathrm{AME}, \mathrm{SME}$, and $\mathrm{BME}$ under RCP4.5 (RCP8.5) is 1.10 to $3.69{ }^{\circ} \mathrm{C}\left(3.49\right.$ to $\left.6.34{ }^{\circ} \mathrm{C}\right)$, 1.10 to $3.69{ }^{\circ} \mathrm{C}\left(3.76\right.$ to $\left.6.34{ }^{\circ} \mathrm{C}\right)$, and 2.11 to $3.22{ }^{\circ} \mathrm{C}$ (4.36 to $\left.5.95{ }^{\circ} \mathrm{C}\right)$, respectively. 

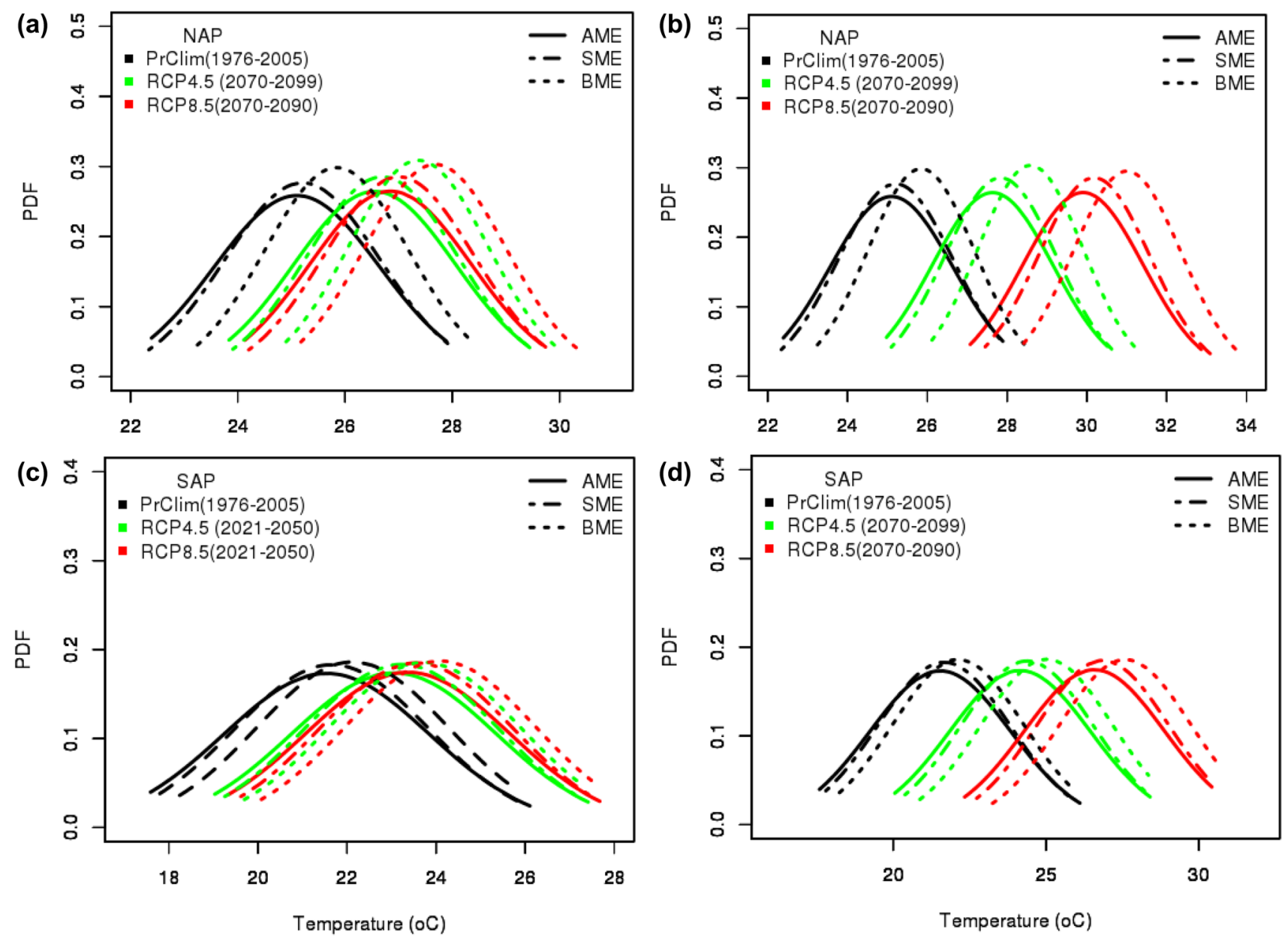

Fig. 10 Simulated mean temperature for present day and future periods over northern $(\mathbf{a}, \mathbf{b})$ and southern $(\mathbf{c}, \mathbf{d})$ Arabian Peninsula. The solid, dashed, and dotted green (red) lines shows simulated temperature for three model ensembles AME, SME, and BME for the future

It is to be noted that the future climate projections based on the multimodel ensembles are not free from uncertainties. The progress in climate modeling in terms of narrowing uncertainties is too limited, although the CMIP5 models are improved compared to the previous generation, with representation of more processes in greater detail. This implies great confidence in their projections and the uncertainties should not stop decisions being made (Knutti and Sedlacek

periods 2021-2050 and 2070-2099 under RCP4.5 (RCP8.5) scenarios. The black, green and red colors indicate the temperature for present day, future RCP4.5, and future RCP8.5 climates over the Arabian Peninsula

2012). The current results demonstrate that selected CMIP5 model over a particular region may reduce the uncertainties associated with climate projections. The results presented in this study provides more reliable future temperature and precipitation estimates with a reduced uncertainty range, that can be used for climate change adaptation measures including impact studies and long-term planning in the Arabian Peninsula. 


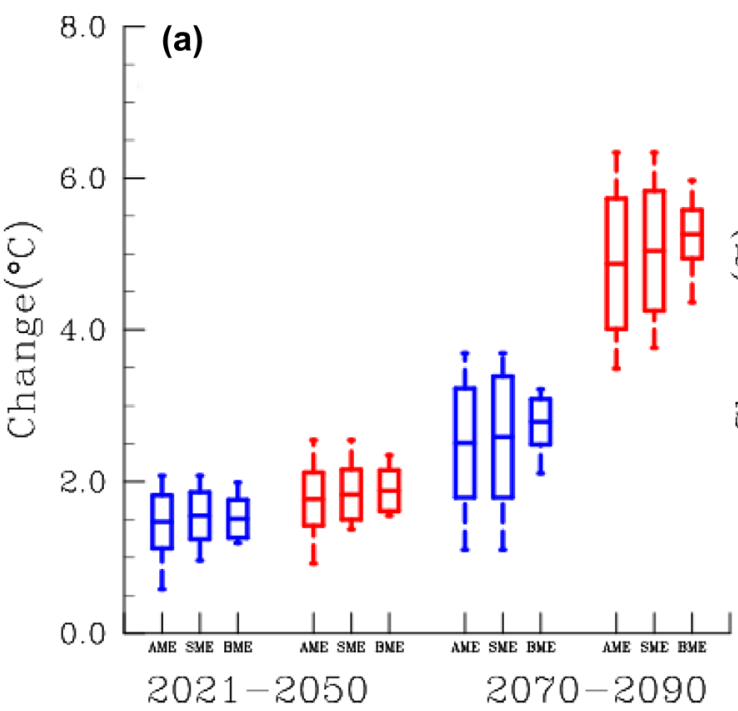

Fig. 11 Box and whisker plots shows a temperature change for the future periods 2021-2050 and 2070-2099 w.r.t. the base period 1976-2005 for AME, SME, and BME. The blue (red) colors show the RCP4.5 (RCP8.5) scenarios. The band in the box represents the change in MME mean; the bottom (top) of the box represents the

Acknowledgements This study has been carried out under the project (award number AT-35-205) funded by the King Abdulaziz City for Science and Technology. The authors thank Prof. Dr. Nicole van Lipzig, Department of Earth and Environmental Sciences, KU Leuven, Belgium for providing necessary facilities and guidance during this research work. Computation for the work described in this paper was performed using Aziz Supercomputer at King Abdulaziz University's High Performance Computing Center, Jeddah, Saudi Arabia.

Open Access This article is distributed under the terms of the Creative Commons Attribution 4.0 International License (http://creativecommons.org/licenses/by/4.0/), which permits unrestricted use, distribution, and reproduction in any medium, provided you give appropriate credit to the original author(s) and the source, provide a link to the Creative Commons license, and indicate if changes were made.

\section{References}

Al Sarmi SH, Washington R (2011) Recent observed climate change over the Arabian Peninsula. J Geophys Res 116:D11

Al Sarmi SH, Washington R (2013) Changes in climate extremes in the Arabian Peninsula: analysis of daily data. Int J Climatol 34:1329-1345

Almazroui M, Awad AM (2016) Synoptic regimes associated with the eastern Mediterranean wet season cyclone tracks. Atmos Res 180:92-118

Almazroui M, Islam MN, Athar H, Jones PD, Rahman MA (2012a) Recent climate change in the Arabian Peninsula: annual rainfall and temperature analysis of Saudi Arabia for 1978-2009. Int J Climatol 32:953-966

Almazroui M, Islam MN, Jones PD, Rahman MA (2012b) Recent climate change in the Arabian Peninsula: seasonal rainfall and temperature climatology of Saudi Arabia for 1979-2009. Atmos Res 111:29-45

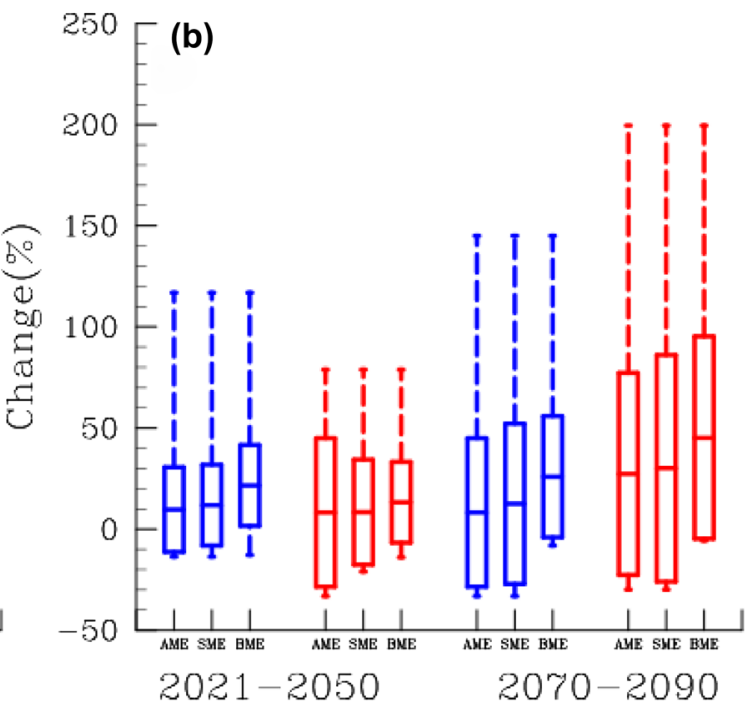

MME mean change \pm one standard deviation. The ends of the whiskers represent the inter-model range, i.e., maximum and minimum changes in the MME w.r.t. base period. b same as (a) except showing precipitation change

Almazroui M, Abid MA, Athar H, Islam MN, Ehsan MA (2013) Interannual variability of rainfall over the Arabian Peninsula using the IPCC AR4 Global Climate Models. Int J Climatol 33:2328-2340

Almazroui M, Saeed F, Islam MN, Al-Khalaf AK (2016) Assessing the robustness and uncertainties of projected changes in temperature and precipitation in AR4 Global Climate Models over the Arabian Peninsula. Atmos Res 15:163-175

Almazroui M, Islam MN, Saeed F, Alkhalaf AK, Dambul R (2017a) Assessing the robustness and uncertainties of projected changes in temperature and precipitation in AR5 Global Climate Models over the Arabian Peninsula. Atmos Res 194:202-213

Almazroui M, Saeed S, Islam MN, Khalid MS, Alkhalaf AK, Dambul R (2017b) Assessment of uncertainties in projected temperature and precipitation over the Arabian Peninsula: a comparison between different categories of CMIP3 models. Earth Syst Environ 1:12. https://doi.org/10.1007/s41748-017-0012-z

Barnes EA, Polvani L (2013) Response of midlatitude jetsm and their variability, to increased greenhouse gases in the CMIP5 models. J Clim. https://doi.org/10.1175/JCLI-D-12-00536.1

Deng L, McCabe MF, Stenchikov G, Evans J, Kucera P (2015) Simulation of flash-flood producing storm events in Saudi Arabia using the Weather research and Forecasting model. J Hydrometeorol. https://doi.org/10.1175/JHM-D-14-0126.1

Di T, Yan G, Wenjie D (2015) Future changes and uncertainties in temperature and precipitation over China based on CMIP5 models. Adv Atmos Sci 32:487-496

Donat MG, Peterson TC, Brunet M, King AD, Almazroui M, Kolli RK, Boucherf D, Al-Mulla AY, Nour AY, Aly AA, Nada TAA, Semawi MM, Al Dashti HA, Salhab TG, El Fadli KI, Muftah MK, Dah Eida S, Badi W, Driouech F, El Rhaz K, Abubaker MJY, Ghulam AS, Erayah AS, Mansour MB, Alabdouli WO, Al Dhanhani JS, Al Shekaili MN (2014) Changes in extreme temperature and precipitation in the Arab region: long-term trends and variability related to ENSO and NAO. Int J Climatol 34:581-592

El Kenawy AM, Stenchikov GL, Raj J (2014) Multi-decadal classification of synoptic weather types, observed trends and links to 
rainfall characteristics over Saudi Arabia. Front Environ Sci 2:37. https://doi.org/10.3389/fenvs.2014.00037

Evans JP (2009) 21st century climate change in the Middle East. Clim Change 92:417-432

Haensler A, Saeed F, Jacob D (2013a) Assessing the robustness of projected precipitation changes over central Africa on the basis of a multitude of global and regional climate projections. Clim Change 121:349-363

Haensler A, Saeed F, Jacob D (2013b) Assessment of projected climate change signals over central Africa based on a multitude of global and regional climate projections. American Geophysical Union, Spring meeting 2013, abstract\#A34A-07

Harris I, Jones PD, Osborn TJ, Lister DH (2014) Up -dated high-resolution grids of monthly climatic observations - the CRU TS3.10 dataset. Int J Climatol 34:623-642

Hawkins E, Sutton R (2009) The potential to narrow uncertainty in regional climate predictions. Bull Am Meteorol Soc. https://doi. org/10.1175/2009BAMS2607.1

IPCC (2001) Climate change 2001: third assessment report of the intergovernmental panel on climate change. Cambridge University Press, Cambridge

IPCC (2013) Climate change 2013: the physical science basis Contribution of Working Group I to the Fifth Assessment Report of the Intergovernmental Panel on Climate Change, Stocker TF, Qin D, Plattner GK, Tignor M, Allen SK, Boschung J, Nauels A, Xia Y, Bex V, Midgley PM (eds). Cambridge University Press, Cambridge

Kendall MG (1976) Rank correlation methods, 4th edn. Griffin, London Knutti R, Sedlacek J (2012) Robustness and uncertainties in the new CMIP5 climate model projections. Nat Clim Change 3:369-373

Kwarteng AY, Dorvlo AS, Kumar GTV (2009) Analysis of a 27-year rainfall data (1977-2003) in the Sultanate of Oman. Int J Climatol 29:605-617
Levine RC, Turner AG, Marathayil D, Martin GM (2013) The role of north Arabian Sea surface temperature biases in CMIP5 model simulations and future projections of Indian summer monsoon rainfall. Clim Dyn 41:155-172

Menon A, Levermann A, Schewe J, Lehmann J, Frieler K (2013) Consistent increase in Indian monsoon rainfall and its variability across CMIP5 models. Earth Syst Dynam 4:287-300

Moss RH et al (2010) The next generation of scenarios for climate change research and assessment. Nature 463:747-756

Pal JS, Eltahir EAB (2016) Future temperature in southwest Asia projected to exceed a threshold for human adaptability. Nat clim Change 6:197-200

Pincus R, Batstone CP, Hofmann RJP, Taylor KE, Glecker PJ (2008) Evaluating the present-day simulation of clouds, precipitation, and radiation in climate models. J Geophys Res 13:D14209

Qian Y, Jackson CS, Giorgi F, Booth B, Duan Q, Forest C, Higdon D, Hou Z, Huerta G (2016) "Uncertainty quantification in climate modeling and projection. Bull Am Meteorol Soc 97(5):821-824. https://doi.org/10.1175/BAMS-D-15-00297.1

Schär C (2016) The worst heat waves to come. Nat Clim Change 6:128-129

Taylor KE, Stouffer RJ, Meehl GA (2012) An overview of Cmip5 and the experiment design. Bull Am Meteorol Soc 93:485-498

Watterson IG, Bathols J, Heady C (2013) What influences the skill of climate model over the continents? Bull Am Meteorol Soc. https:// doi.org/10.1175/BAMS-D-12-00136.1

Weigel AP, Liniger MA, Appenzeller C (2008) Can multimodel combination really enhance the prediction skill of probabilistic ensemble forecasts? Q J Roy Meteorol Soc 134:241-260

Zhao L, Xu J, Powell AM Jr, Jiang Z (2015) Uncertainties of the global-to-regional temperature and precipitation simulations in CMIP5 models for past and future 100 years. Theor Appl Climatol 122:259-270 